\title{
ANALYSIS OF UNSTEADY FLOW IN COMPLEX PIPE SYSTEM BY THE METHOD OF CHARACTERISTICS
}

\author{
Tekin TEZCAN, Ümit GÖKKUŞ and Gültekin SINIR \\ Celal Bayar University, Faculty of Engineering, Department of Civil Engineering \\ Muradiye Campus, Manisa, TURKEY
}

\begin{abstract}
This study aims at the unsteady flow analysis of complex pipe system by using the method of characteristics. Excess demand and sudden closure and opening of devices such as valves and pumps causes the occurrence of unsteady flow. Hydraulic analysis of pipe system is still performed only by steady-state flow. The unsteady flow analysis can be done by using the results of this analysis.
\end{abstract}

\section{INTRODUCTION}

The hydraulic analysis of flow in complex pipe systems is usually based upon the consideration of steady state conditions. By applying some combination of the conservation of mass equation, the work-energy (Bernoulli) equation and the impulse-momentum equation, all problems in the hydraulics of pipe systems are solved. To compute the head losses containing the normal pipe friction which results from the persistent effect of wall friction along the full length of the pipe and minor losses resulting from increased flow disruption caused by valves, fittings, bends, and so on, the Darcy-Weisbach, Hazen-Williams and Manning formulas are mostly used today. The steady state pipeline analysis requires selecting a pipe diameter which will convey the amount of discharge between two location of known elevation with specified reservoir surface elevations or pressure requirements. The Darcy-Weisbach formula is the most general in application. It can be used for a variety of liquids and gases, for laminar and turbulent flow, and for rough or smooth pipes. Its main disadvantage is the fact that the friction factor $\mathrm{f}$ is often dependent on one of the design unknowns (pipe diameter or discharge) and a trial solution results. However, engineers are increasingly using this formula because of its breadth of application and its simplification by using the computer techniques. The Hazen-Williams formula does not give accurate results for rough pipes, small pipes or laminar flow. The Manning formula should be used only for the flow of water in rough pipes.

The hydraulic analysis can be easily performed for the single pipelines with or without pumps, branching and looping pipelines. But the steady state analysis of flows in pipe networks can be a very complex problem. Devices such as pressure reducing valves, minor losses, booster pumps and supply pumps, as well as reservoir, causes the complication of this analysis. However, the flow in pipe network can be analyzed by using one of the three most popular analysis methods: the Hardy-Cross method, the Linear Theory method and the Newton-Raphson method. The Hardy-Cross method still enjoys considerable popularity among practicing engineers because of its simplicity 
of application, its easily understood theory and its amenability to hand calculation. It assumes that a unique flow rate adjustment can be found which can be applied to each loop in the network. The Linear theory method is a technique for solving a set of network equation, some of which are nonlinear, for the unknown flow rates in the pipes. The Newton-Raphson technique has the same conceptually basis as the HardyCross method. Flow rates in each pipe are assumed which satisfy continuity and these flow rates are corrected so that the sum of the head losses around each loop approaches zero.

The engineer designing liquid conveyance systems is frequently faced with selecting the pump types and determining the locations of hydraulic control devices and problem. During the operation of pipe network, the internal flow sometimes changes with external interference to flow and the fluctuations through pipe happen. In this case, the steady state is no longer considered and it is no longer necessary to confine the mathematical modeling of a network to that of steady state. The liquid body is accelerated by such effect applied to fluid flow. A sound that resembles the noise that occurs when a pipe is struck by hammer generates through pipe and a steep pressure wave front propagates due to this motion. Therefore, such pressure transients to occur are called as waterhammer. The flow conditions transforms to the unsteady state.

Unsteady flow problems in engineering practice are of significant importance because they can cause excessive pressures, vibration, cavitation, and noise far beyond that indicated by steady flow analysis. In fact, the problems resulting from the hydraulic transients may create different failure effects on a pipe system depending on the physical configuration of the system, the mechanical components in the system, the physical properties of the pipe and liquid and the existence of free air in the system.

Unsteady state analysis can include steady state analysis as a special case. Initial condition of hydraulic transients, the behavior of pipe system will be as that of steady state analysis. After that, the motion through pipe will propagate with the time as it is seen in wave motion. In a pipe network, the hydraulic transients and waterhammer can result from the following situations:

1. Sudden change of external flow demand at a junction due to fire demand or valve closure.

2. Sudden valve opening or closure

3. Valves can be opened or closed with the time varying change

4.Pomp power failure

To analyze the unsteady flow problems, the rigid water column theory, the elastic theory or the method of characteristics are used $[8,9]$.

\section{ELASTIC THEORY}

Pressure waves which result from the velocity changes depend on the pipe and fluid elastic properties and they propagate throughout the pipeline system at speeds depending directly on these elastic properties. While elastic theory more accurately reflects the behavior of the unsteady flow system, successful analysis hinges on the 
ability to solve two nonlinear partial differential equations. As a consequence, the analysis is more complex and difficult to manage than for inelastic theory.

To analyze unsteady flow problems in pipe system, an equation with an approach based on the Newton's Second Law is developed by considering a small cylindrical fluid particle at the centerline (Fig.1).

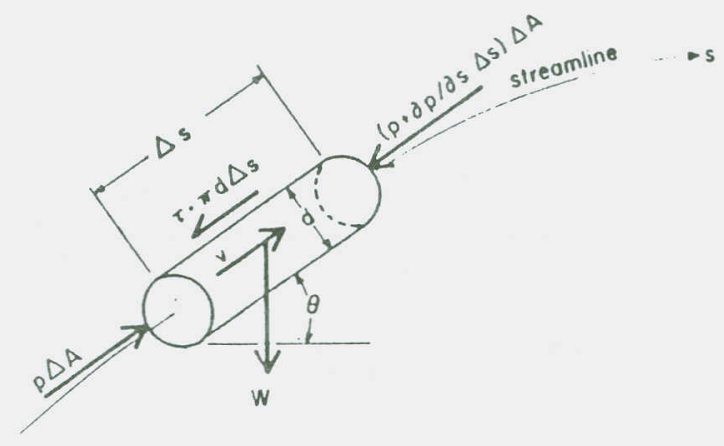

Fig. 1. Definition Sketch for Unsteady Flow Equation Derivation

The resulting differential equation of unsteady flow is known as one-dimensional Euler equation (9)

$$
\mathrm{p} \Delta \mathrm{A}-\left(\mathrm{p}+\frac{\partial \mathrm{p}}{\partial \mathrm{s}} \Delta \mathrm{s}\right) \Delta \mathrm{A}-\mathrm{W} \sin \theta-\tau \Delta \mathrm{s} \pi \mathrm{d}=\frac{\mathrm{W}}{\mathrm{g}} \frac{\mathrm{dv}}{\mathrm{dt}}
$$

where $\mathrm{m}$ is the fluid particle mass, $\mathrm{s}$ is the streamline direction, $\mathrm{D}$ is the pipe diameter, $\tau_{0}$ is the shear stress at the wall and $\mathrm{V}$ is the average velocity.

For the circular cylindrical pipes, wall shear can be expressed by the Darcy-Weisbach friction factor (9)

$-\frac{1}{\gamma} \frac{\partial \mathrm{p}}{\partial \mathrm{s}}-\frac{\partial \mathrm{z}}{\partial \mathrm{s}}-\frac{4 \tau_{\mathrm{o}}}{\gamma \mathrm{D}}=\frac{1}{\mathrm{~g}} \frac{\mathrm{dV}}{\mathrm{dt}}$

Substituting this equation into Equation (2) gives

$$
\frac{\mathrm{dV}}{\mathrm{dt}}+\frac{1}{\rho} \frac{\partial \mathrm{p}}{\partial \mathrm{s}}+\mathrm{g} \frac{\partial \mathrm{z}}{\partial \mathrm{s}}+\frac{\mathrm{f}}{2 \mathrm{D}} \mathrm{V}|\mathrm{V}|=0
$$

It is appropriate to point out at this time that both $\mathrm{V}$ and $\mathrm{p}$ are functions of time $\mathrm{t}$ and location $\mathrm{s}$ along the pipe. The term $\partial \mathrm{z} / \partial \mathrm{s}$ is the slope of the pipe and can be written as the total derivative dz/ds. Equation (3) is an equation with two dependent variables $\mathrm{V}(\mathrm{s}, \mathrm{t})$ and $\mathrm{p}(\mathrm{s}, \mathrm{t})$ hence is a second equation relating the same dependent variables. 
To obtain this equation the conservation of mass is applied to a control volume coinciding with the interior of the pipe and of length ds. Conservation of mass gives Equation (8)

$$
\begin{aligned}
& \rho \mathrm{AV}-\left[\rho \mathrm{AV}+\frac{\partial}{\partial \mathrm{s}}(\rho \mathrm{AV}) \mathrm{ds}\right]=\frac{\partial}{\partial t}(\rho \mathrm{Ads}) \\
& -\frac{\partial}{\partial \mathrm{s}}(\rho \mathrm{AV}) \mathrm{ds}=\frac{\partial}{\partial t}(\rho \mathrm{Ads})
\end{aligned}
$$

The ends of the control volume are free to move longitudinally with the pipe. Regrouping and dividing by $\rho$ A.ds, Equation (4) becomes Equation (8)

$\frac{1}{\rho}\left(\frac{\partial \rho}{\partial t}+V \frac{\partial \rho}{\partial s}\right)+\frac{1}{A}\left(\frac{\partial A}{\partial t}+V \frac{\partial A}{\partial s}\right)+\frac{1}{d s} \frac{\partial}{\partial t}(d s)+\frac{\partial V}{\partial s}=0$

because ds, fixed to the pipe walls, varies only with time.

The change in liquid volume can be expressed as the bulk modulus of elasticity of liquid $(\mathrm{K})$ and written as follows;

$$
K=-\frac{d p}{\frac{d \forall}{\forall}}=\frac{d p}{\frac{d \rho}{\rho}}
$$

where $\mathrm{p}$ and $\forall$ are the pressure and volume, respectively.

To develop a useful expression for $\mathrm{dA} / \mathrm{dt}$ in terms of pressure, the elastic pipe deformations must be considered. For stretching of the cross-sectional area, dA/dt can be written as depending on the boundary condition. [9]

$$
\frac{1}{\mathrm{~A}} \frac{\mathrm{dA}}{\mathrm{dt}}=\left(1-\mu^{2}\right) \frac{\mathrm{D}}{\mathrm{eE}} \frac{\mathrm{dp}}{\mathrm{dt}}
$$

Combining all of these terms into Equation (5) results in

$$
\frac{\mathrm{dp}}{\mathrm{dt}}\left[\frac{1}{\mathrm{~K}}+\left(1-\mu^{2}\right) \frac{\mathrm{D}}{\mathrm{eE}}\right]+\frac{\partial \mathrm{V}}{\partial \mathrm{s}}=0
$$

By taking into account the wave speed, a, which is caused by waterhammer,[6] 
$a=\frac{\left[\frac{K}{\rho}\right]^{1 / 2}}{\left[1+\frac{K}{E} \frac{D}{e}\left(1-\mu^{2}\right)\right]^{1 / 2}}$

it is easily seen that the term in brackets is $1 /\left(a^{2} \rho\right)$

Finally, the necessary set of two simultaneous independent partial equations will enable the required possibility to solve for $p(s, t)$ and $V(s, t) .(8)(9)$

$\frac{d V}{d t}+\frac{1}{\rho} \frac{\partial p}{\partial s}+g \frac{d z}{d s}+\frac{f}{2 D} V|V|=0$

$\mathrm{a}^{2} \frac{\partial \mathrm{V}}{\partial \mathrm{s}}+\frac{1}{\rho} \frac{\mathrm{dp}}{\mathrm{dt}}=0$

These two equation, Continuity and Euler equations, will be solved by using the method of characteristics.

\section{SOLUTION BY METHOD OF CHARACTERISTICS}

Unsteady flow analysis can be realized by using the Method of Characteristics derived by finite difference methods, and the Euler and Continuity equations can be easily solved to find the unknown pressure and velocity of fluid in unsteady state. This method can be defined by drawing the s-t coordinate system. The origin of the s-axis (abscissa) is placed at the upstream pipe end and extended in the positive direction along for a distance $\mathrm{L}$ equal to the pipe length. Figure 2 illustrates how the s-t plane can be used to define the pressure wave propagation through the pipe.

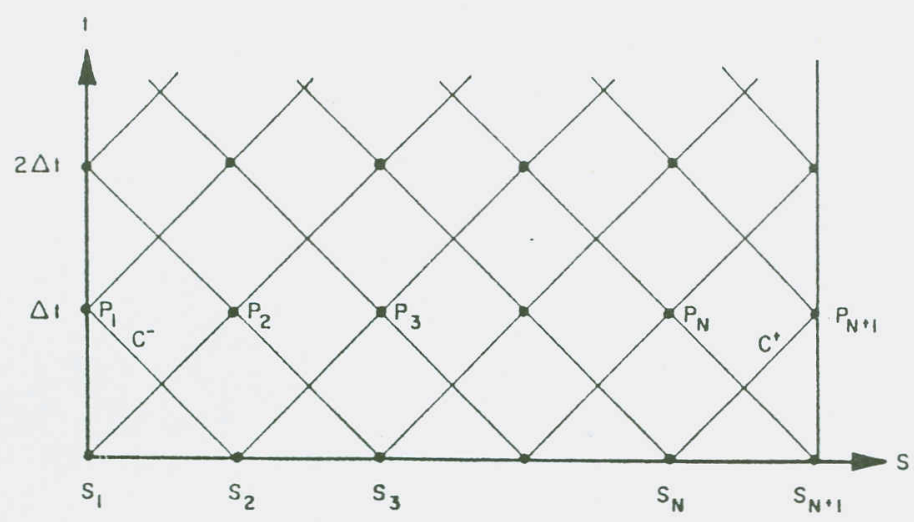

Fig. 2. Definition of s-t plane 
Pipe is divided into $\mathrm{N}$ sections and the interval $\Delta s=\mathrm{L} / \mathrm{N}$ and the time interval $\Delta t$ depending on $\Delta$ s can be calculated as follows; [9]

$\Delta \mathrm{t} \leq \frac{\Delta \mathrm{s}}{\max |\mathrm{a}+\mathrm{V}|}$

In solving the complete equations, the multiplier $\lambda$ is used to combine the two partial differential equations. Multiplying $\lambda$ by Equation (10) and adding the result to Equation (11) gives[8]

$\lambda \frac{d V}{d t}+\frac{\lambda \partial p}{\rho \partial s}+\lambda g \frac{d z}{d s}+\frac{\lambda f}{2 D} V|V|+a^{2} \frac{\partial V}{\partial s}+\frac{1}{\rho} \frac{d p}{d t}=0$

The final set of equations can be derived as follows; [9][8]

$\mathrm{C}^{+}: \frac{\mathrm{dV}}{\mathrm{dt}}+\frac{\mathrm{g} d \mathrm{H}}{\mathrm{a}} \mathrm{dt}-\frac{\mathrm{g}}{\mathrm{a}} \mathrm{V} \frac{\mathrm{dz}}{\mathrm{ds}}+\frac{\mathrm{f}}{2 \mathrm{D}} \mathrm{V}|\mathrm{V}|=0$ only if $\frac{\mathrm{ds}}{\mathrm{dt}}=\mathrm{V}+\mathrm{a}$

$C^{-}: \frac{d V}{d t}-\frac{g}{a} \frac{d H}{d t}+\frac{g}{a} V \frac{d z}{d s}+\frac{f}{2 D} V|V|=0$ only if $\frac{d s}{d t}=V-a$

According to these equations, the characteristic lines on the s-t plane are curved and their slope is a function of $\mathrm{V}(\mathrm{s}, \mathrm{t})$. The curved characteristics intersecting at P (Fig. 3) are approximated by straight lines. The slopes of the straight lines are determined by the known value of velocity.

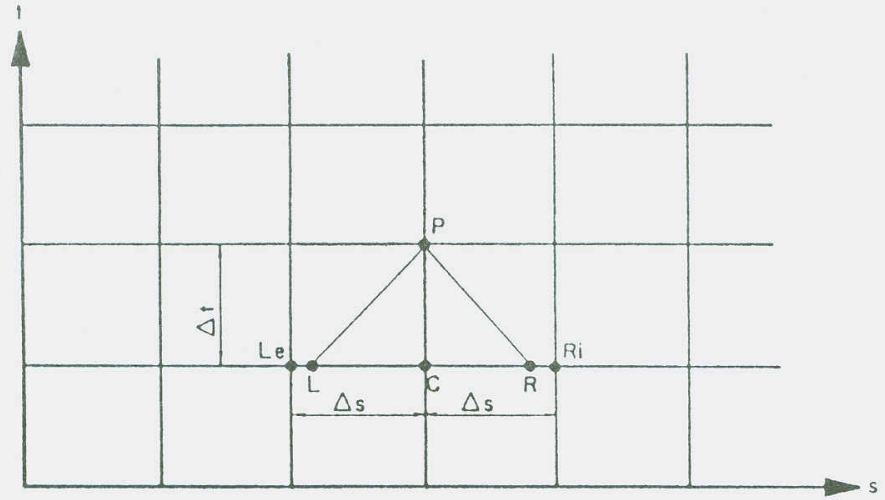

Fig. 3.Interpolation of $\mathrm{H}$ and $\mathrm{V}$ values on a s-t plane

The simultaneous solution of Equation (14) and (15) for $\mathrm{V}_{\mathrm{P}}$ and $\mathrm{H}_{\mathrm{P}}$ gives [8][7]

$$
V_{P}=\frac{1}{2}\left[\left(V_{L}+V_{R}\right)+\frac{g}{a}\left(H_{L}-H_{R}\right)+\frac{g}{a} \Delta t\left(V_{L}-V_{R}\right) \sin \theta\right.
$$




$$
\begin{aligned}
& \left.-\frac{f \Delta t}{2 D}\left(V_{L}\left|V_{L}\right|+V_{R}\left|V_{R}\right|\right)\right] \\
H_{P}=\frac{1}{2} & {\left[\left(H_{L}+H_{R}\right)+\frac{a}{g}\left(V_{L}-V_{R}\right)+\Delta t\left(V_{L}+V_{R}\right) \sin \theta\right.} \\
& \left.-\frac{a}{g} \frac{f \Delta t}{2 D}\left(V_{L}\left|V_{L}\right|+V_{R}\left|V_{R}\right|\right)\right]
\end{aligned}
$$

where $\sin \theta=\mathrm{dz} / \mathrm{ds}$ (positive for pipes sloping upward in downstream direction)

At the beginning of calculation, $\mathrm{V}_{\mathrm{LE}}, \mathrm{H}_{\mathrm{LE}}, \mathrm{V}_{\mathrm{Rl}}, \mathrm{H}_{\mathrm{Rl}}$ are known in accordance with the results of steady state analysis. The unknown values of $\mathrm{H}$ and $\mathrm{V}$ at points $\mathrm{L}$ and $\mathrm{R}$ can be estimated by linear interpolation.

In series pipes, each pipe carries the same steady flow discharge, but has its own values of velocity, diameter, wave speed, and so on. The grid system for each pipe is drawn separately and the ordinate points on intersection of one pipe should fit into that of other pipe. In these points, there have been same pressures and velocities. The same rule is also applied for branching pipes.

\section{ANALYSIS OF COMPLEX PIPE SYSTEM}

According to the above-mentioned unsteady flow equations and the numerical solution on the method of characteristics, the computer program is coded [3][9] and the water distribution network seen in Fig. 4 is analyzed hydraulically. The required data for running the program are submitted as below.

The steady state situation is first solved and the input data to accomplish this are listed The data required to analyze the water hammer problem resulting from a suddenly closed valve at the downstream end of pipe 8 are shown. The results including the time dependent pressure and velocity are graphically presented in Fig.5a.b.

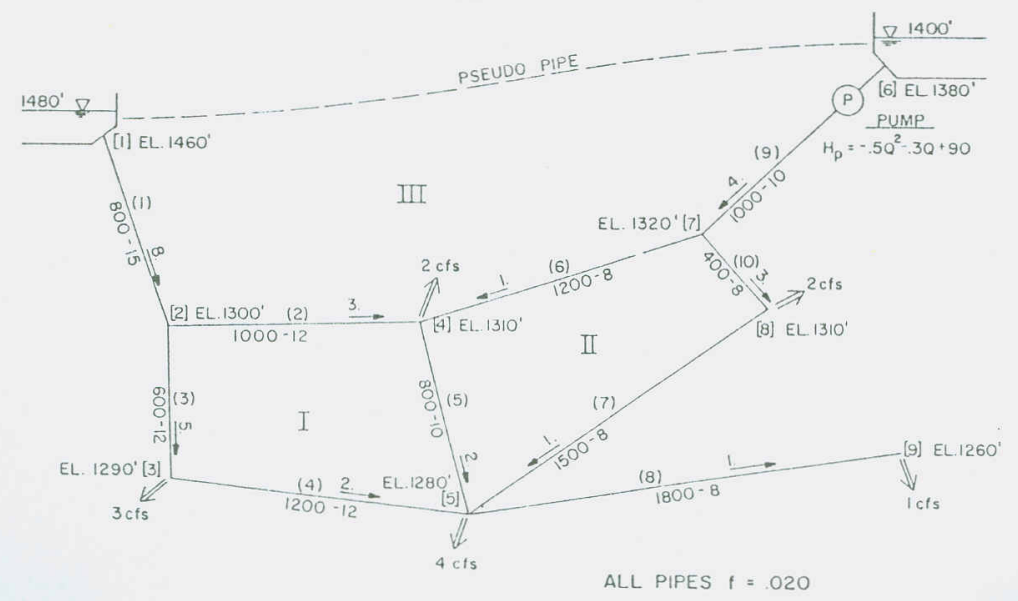

Fig.4. Pipe system with a single pipe extending from network 


\section{Data description}

Number of pipe and node, respectively $=10,9$

Atmospheric pressure head

$=32.20 \mathrm{ft}$.

Maximum real time of simulation $\quad=5.00 \mathrm{sec}$.

Time interval

$=0.04 \mathrm{sec}$.

Number of parts into which pipe is divided $=3$

Number of discharge nodes from network $=5$

Discharge at the node $3=3.0 \mathrm{gpm}$

Discharge at the node $4=2.0 \mathrm{gpm}$

Discharge at the node $5=4.0 \mathrm{gpm}$

Discharge at the node $8=2.0 \mathrm{gpm}$

Discharge at the node $9=1.0 \mathrm{gpm}$

Number of pipe where the two-stage valve is placed $\quad=7$

Time when first stage of valve closure is completed $\quad=0.04 \mathrm{sec}$

Percent open of valve at the end of stage one $\quad=(\%) 2$

Time when second stage of valve closure is completed $=2.00 \mathrm{sec}$.

Number of valve with suddenly closing

$=2$

Array of pipe number with suddenly closing at the downstream end $=1$

Array of pipe number with suddenly closing at the downstream end $=9$

\section{Data on pipes}

\begin{tabular}{|c|c|c|c|c|c|c|c|c|c|}
\hline $\begin{array}{l}\text { Pipe } \\
\text { no }\end{array}$ & $\begin{array}{l}\text { Dia. } \\
\text { (inch) }\end{array}$ & $\begin{array}{l}\text { Pipe } \\
\text { Length }\end{array}$ & $\begin{array}{l}\text { Wave } \\
\text { Speed }\end{array}$ & $\begin{array}{l}\text { Elevation } \\
\text { (ft) }\end{array}$ & $\begin{array}{l}n \text { fric. } \\
\text { coeff. }\end{array}$ & $\begin{array}{l}\text { initial } \\
\text { velocity }\end{array}$ & $\begin{array}{l}\text { time } \\
\text { (sec) }\end{array}$ & $\begin{array}{l}\text { Division } \\
\text { Number }\end{array}$ & $\begin{array}{l}\text { Head } \\
\text { Slope }\end{array}$ \\
\hline 1 & 15 & 800 & 3300 & 1460 & 0.020 & 6.519 & 0.081 & 6 & -0.200 \\
\hline 2 & 12 & 1000 & 3300 & 1300 & 0.020 & 3.820 & 0.101 & 8 & 0.010 \\
\hline 3 & 12 & 600 & 3300 & 1300 & 0.020 & 6.366 & 0.060 & 5 & -0.017 \\
\hline 4 & 12 & 1200 & 3300 & 1290 & 0.020 & 2.546 & 0.121 & 9 & -0.008 \\
\hline 5 & 10 & 800 & 3300 & 1310 & 0.020 & 3.667 & 0.081 & 6 & -0.038 \\
\hline 6 & 8 & 1200 & 3300 & 1320 & 0.020 & 2.865 & 0.121 & 9 & -0.008 \\
\hline 7 & 8 & 1500 & 3300 & 1310 & 0.020 & 2.865 & 0.151 & 11 & -0.020 \\
\hline 8 & 8 & 1800 & 3300 & 1280 & 0.020 & 2.865 & 0.182 & 14 & -0.011 \\
\hline 9 & 10 & 1000 & 3300 & 1380 & 0.020 & 7.334 & 0.101 & 8 & -0.060 \\
\hline 10 & 8 & 400 & 3300 & 1320 & 0.020 & 8.594 & 0.040 & 3 & -0.025 \\
\hline
\end{tabular}

\section{Data on Nodes}

\begin{tabular}{cccc} 
Node no & Pressure head $(\mathrm{ft})$ & Elevation of nodes & Discharge \\
\hline 1 & 1480.00 & 1460.00 & -8.00 \\
2 & 1470.20 & 1300.00 & -0.00 \\
3 & 1462.00 & 1290.00 & 0.01 \\
4 & 1464.50 & 1310.00 & 0.00 \\
5 & 1459.10 & 1280.00 & 0.01 \\
6 & 1400.00 & 1380.00 & -4.00 \\
7 & 1468.60 & 1320.00 & -2.00 \\
8 & 1459.40 & 1310.00 & 0.00 \\
9 & 1454.90 & 1260.00 & 0.00
\end{tabular}




\section{Outputs}

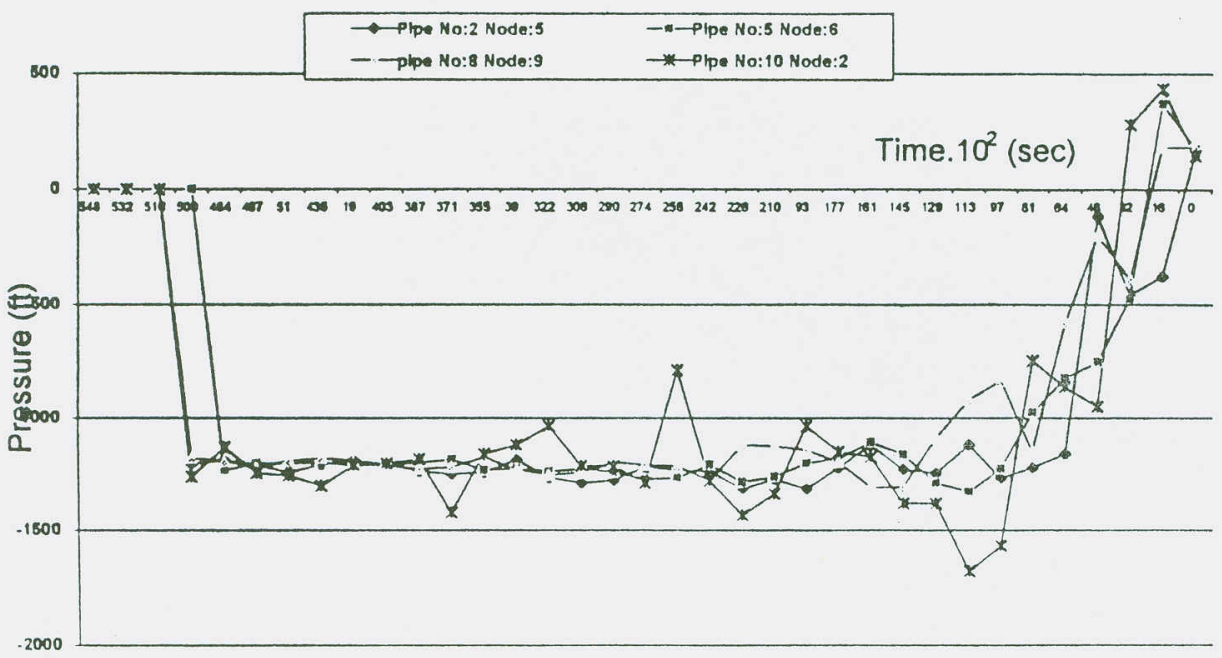

Figure.5a. Pressure head resulting from the unsteady flow at the considered nodes

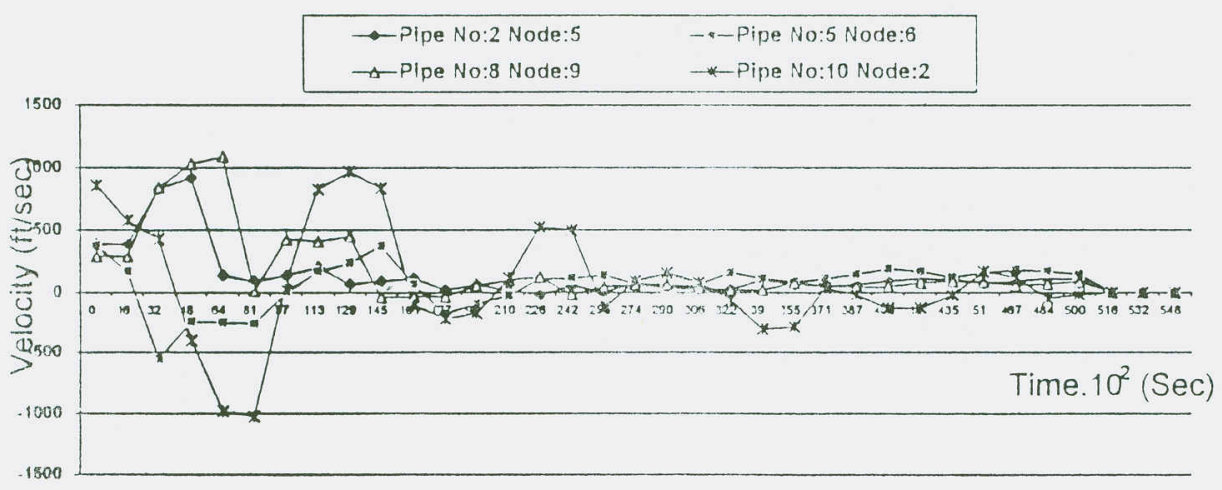

Figure $5 b$. Velocities resulting from the unsteady flow at the considered nodes

\section{CONCLUSION}

Generally, the hydraulic analysis of water distribution network is performed by considering the steady state situation. For the solution, one of the three methods containing generally the Hardy-Cross, the Linear Theory or The Newton-Raphson method is preferred to find the pressure and velocity at any point in network. But the steady state situation can change during the operation of pipe system. A pump and control device place at any pipe on network causes this occurrence. Suddenly pressure and velocity of the flow through pipe change. Pipe failure can happen unless the pipe 
wall is strengthened enough. Before coming face to face with this case, the unsteady flow analysis is taken into consideration. During the hydraulic calculations, the two partial differential equations, the Euler and Continuity equations, are mostly solved by using the method of characteristics based on the finite difference approximation. Of course that the computer program developed for this job enables the certain ease for the engineers interested in it.

As seen in Fig. 5a.b. the excess negative pressures can be determined by suddenly valve closure. In accordance with this pressure, the selection of the pipe material and the required thickness can be determined. This study aims at the widely use of unsteady flow analysis in engineering practice.

\section{REFRENCES}

1. O. C. Young and J. J. Trott, Buried Rigid Pipes-Simuchural Design of P'ipelines, Elsevier Applied Science Publishers, 1984

2. H. Arthur and W. W. Hurlbut, Fundamentals on Use and Design of Steel Pipe's, AWWA Manual M1 1 (American Water Works Association) 1982.

3. S. Sevïk and D. Altubilek, (omputer - Aided Design of Water Distribution Network, Middle East Technical University, Publication No: 56, 1982

4. W. L. Streeter and E. B. Wylie, Fhid Mechanics, Mc Graw Hill, New York, 1983

5. A. Chadwick and J. Morfett, Hydranlics in Civil and Envirommental Engineering, Pitman Co., New York, 1992.

6. J. Parmakian, Waterhammer Analysis, Dover, New York, 1963

7. E. B. Wylie, The Microcomputer and Pipeline Transients, American Society of Civil Engineers, Journal of Hydraulic Engineering 109, 1723-39, 1989.

8.G.Z.Watters, Analysis and Control of Unsteady Flow in Pipelines, Butterworths Co., 1983 .

9. J. A. Fox, Hydraulic Analysis of Unsteady Flow in Pipe Networks, John Wiley \& Sons, New York, 1977

10.J.Vincent -Genod, Fundamentals of Pipeline Engineering, Gulf Publishing Co., Houston, 1991.

11. Ü. Gökkus , G. Durgun, The Pipe-Soil-Fluid Interaction in Pipe Systems, Chamber of Civil Engineers, Pub.no: 61, 1995. 